\title{
Response surface optimization of ultrasonic assisted extraction of flavonoids from Brucea javanica
}

\author{
Aiping Fei, Junyu Jiang, Yong Wang, Zhigang Fang, Yingxue Teng, Xiaoliang Hao* \\ University of Science and Technology Liaoning, Anshan China, 114000
}

\begin{abstract}
This text was mainly studied the response surface optimization of ultrasonic assisted extraction of flavonoids from Brucea javanica. The optimum extraction process conditions were obtained by color reaction to prove the presence of flavonoids and by response surface simulation and quantification, the optimum condition was: ethanol concentration was $90 \%$, the ratio of liquid to solid was $10: 1$, and the extraction time was $2 \mathrm{~h}$, the total extraction rate was the largest, up to about $1.43 \%$.
\end{abstract}

\section{INTRODUCTION}

Brucea javanica is the mature seed of Brucea javanica (Simaroubaceae), also known as Hazelnut, Sophora flavescens and so on. It is mainly in China's Guangdong and Guangxi provinces, and is rich in resources. The main chemical constituents from Brucea javanica are bitter lignans, flavonoids, triterpenoids and alkaloids. These ingredients are great of using in the field of medicine and human health. Many researchers have studied the chemical constituents of Brucea Javanica ${ }^{[1-4]}$. With the continuous development of plant extraction technology, various chemical components in Brucea Javanica are extracted by people for scientific research ${ }^{[5-7]}$. Especially, the anti-cancer effect of Brucea javanica oil has been paid more attention ${ }^{[8-13]}$, and the anti-cancer effect of Brucea javanica oil has been extensively studied. It is reported that flavonoids have anti-inflammatory and analgesic effects. In this study, flavonoids were extracted from Brucea javanica, hoping to provide references for further processing and utilization of traditional Chinese medicine ${ }^{[14]}$.

\section{MATERIALS AND METHODS}

\subsection{Materials}

Brucea javanica was bought from the local supermarket. Anhydrous ethanol, sodium nitrite, aluminum sulfate, sodium hydroxide were bought from Beijing North Chemical Fine Chemicals Co., Ltd. Rutin, saffron red, o-phenol, disodium hydrogen phosphate, sodium dihydrogen phosphate, and sodium dihydrogen phosphate were bought from National drug group chemical reagents Co., Ltd. All the reagents were analytically pure.

\footnotetext{
a Corresponding author: Haoxiaoliang1980@163.com
}

\subsection{Instruments}

Dfy-400 swing high-speed universal mill (Wenling Linda machinery manufacturing co., LTD); 00000792-1 electronic balance (Zhuji chaoze equalizer equipment co., LTD); Kq-250b ultrasonic cleaner (Kunshan ultrasonic instrument co., LTD); ReactlR 15 type infrared analyzer (German mettler company); 1100 chromatographic analyzer (Agilent company).

\subsection{Experimental}

\subsubsection{Extraction procedure of flavonoids}

Brucea javanica was smashed with mill grinding, the powder weight was $1.00 \mathrm{~g}$, a certain volume fraction of ethanol solution was added, and adjusting the ratio of liquid to solid, put triangular flask which contained the extraction sloution into ultrasonic cleaner, set temperature as $50{ }^{\circ} \mathrm{C}$, set power as $400 \mathrm{~W}$. After extraction, the extraction liquid was filtered by filter paper.

\subsubsection{Drawing of standard curve of rutin}




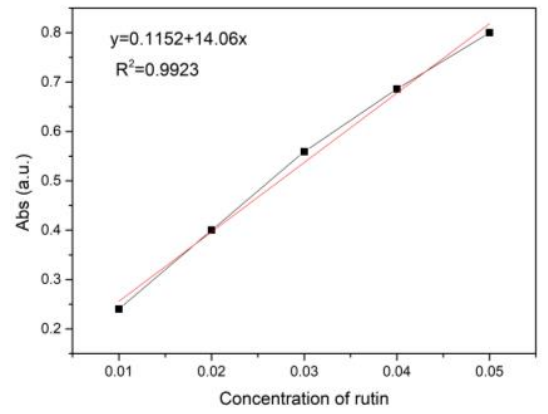

Figure 1. Standard curve of rutin.

\subsubsection{Calculation of flavonoids content}

The flavonoids content $\mathrm{C} \%$ was calculated according to the formula (1).

$$
C(\%)=\frac{V \times X}{100 \times A \times W} \times 100 \%
$$

$\mathrm{X}$ :Content of flavonoids $(\mathrm{mg} / \mathrm{ml})$

$\mathrm{V}$ :Extract volume $(\mathrm{ml})$

A:Sampling volume $(\mathrm{ml})$

$\mathrm{W}:$ Sample weight $(\mathrm{g})$

\subsubsection{Color analysis identification}

The above extracted liquid of Brucea javanica was taken as sample, and color analysis was carried out by UV lamp irradiation, ammonia reaction, and sodium hydroxide reaction.

\section{RESULTS AND DISSCUSSION}

\subsection{Single factor experiment}

\subsubsection{Effect of ratio of liquid to solid on the extraction effect of flavonoids}

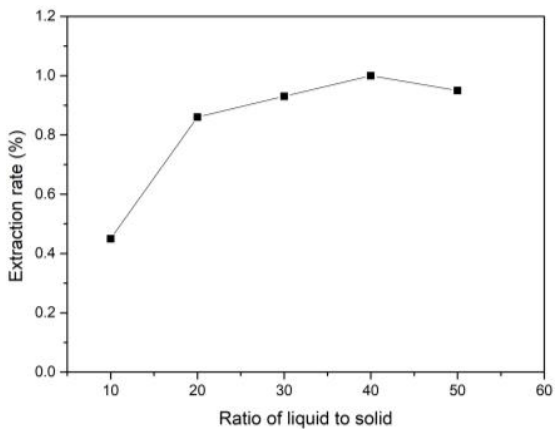

Figure 2. Effect of ratio of liquid to solid on the extraction effect of flavonoids.

As shown in Figure 2, with the increase of ratio of liquid to solid, flavonoids extraction rate in Brucea javanica was first increased and then showed a gentle trend. When the ratio of liquid to solid was too low, the sample could not be completely immersed in the solvent, the extraction was incomplete, and the extraction rate was low. When the ratio was higher than 20:1, the curve showed a gentle trend, indicating that this volume of solvent had reached the extraction effect, which led to waste of solvent. So when the extraction temperature was
$50{ }^{\circ} \mathrm{C}$, the ultrasonic power was $400 \mathrm{~W}$, the ethanol concentration was $70 \%$, extraction time was $2 \mathrm{~h}$, flavonoids extraction rate was better.

\subsubsection{Effect of ultrasonic time on the extraction effect of flavonoids}

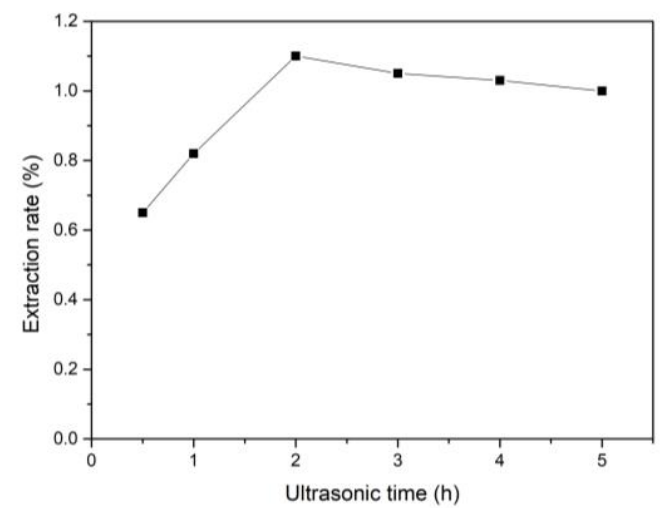

Figure 3. Effect of ultrasonic time on the extraction rate of flavonoids.

As shown in Figure 3, with the increase of ultrasonic time, the extraction rate of flavonoids became higher. After $2 \mathrm{~h}$, the extraction rate of flavonoids decreased slightly, the reason was that the ultrasonic time was too long, caused the instrument temperature more than $50{ }^{\circ} \mathrm{C}$, depressed flavonoids material degeneration. After $2 \mathrm{~h}$, the flavonoids in the sample had been fully extracted, and the further time would only increase the energy consumption. So when the temperature was $50{ }^{\circ} \mathrm{C}$, ethanol concentration was $70 \%$, ultrasonic time was $2 \mathrm{~h}$, flavonoids extraction rate was better.

\subsubsection{Effect of ethanol concentration on the extraction effect of flavonoids}

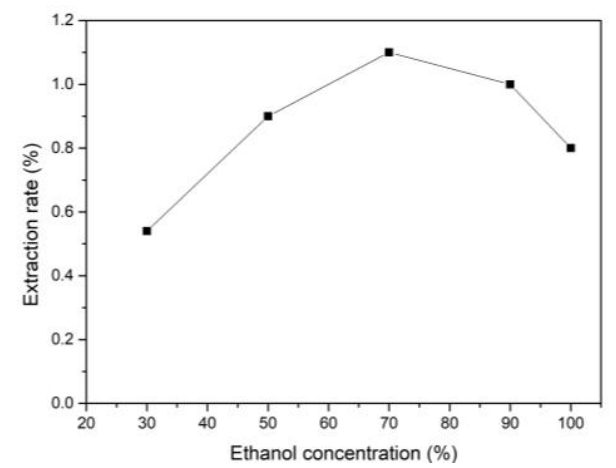

Figure 4. Effect of ethanol concentration on the extraction rate of flavonoids.

With the increase of ethanol concentration, the extraction rate of flavonoids increased first and then decreased (see Figure 4). It might be that if the ethanolconcentration was different and the polarity was different. After the ethanol concentration was over $70 \%$, the extraction rate began to decline greatly, and the dissolution of flavonoids was reduced, while some impurities were increased, leading to the reduction of the extraction rate. So when extraction temperature was $50{ }^{\circ} \mathrm{C}$, ultrasonic time was $2 \mathrm{~h}$, the ethanol concentration was $70 \%$, flavonoids extraction rate was better. 


\subsection{Experimental results of response surface}

The Box Behnken model by software Design Expert 8.0.6 was used to design the response surface experiment. The design parameter contained the ratio of liquid to solid, ultrasonic time and ethanol concentration.

Table 1. Response surface factor and level table.

\begin{tabular}{cccc}
\hline Code & $\begin{array}{l}\text { Ratio of liquid to } \\
\text { solid (A) }\end{array}$ & $\begin{array}{l}\text { Ethanol } \\
\text { concentration (B) }\end{array}$ & Time (C) \\
\hline-1 & $10: 1$ & 50 & 1 \\
0 & $20: 1$ & 70 & 2 \\
1 & $30: 1$ & 90 & 3 \\
\hline
\end{tabular}

Table 2. Design and the results of the response surface.

\begin{tabular}{|c|c|c|c|c|}
\hline No & $\begin{array}{l}\text { Ratio of liquid } \\
\text { to solid (A) }\end{array}$ & $\begin{array}{l}\text { Ethanol } \\
\text { concentration } \\
\text { (B) }\end{array}$ & $\begin{array}{r}\text { Time } \\
(\mathrm{C})\end{array}$ & $\begin{array}{l}\text { Extraction } \\
\text { rate }\end{array}$ \\
\hline 1 & -1 & -1 & 0 & 1.32 \\
\hline 2 & 1 & -1 & 0 & 0.99 \\
\hline 3 & -1 & 1 & 0 & 1.35 \\
\hline 4 & 1 & 1 & 0 & 1.01 \\
\hline 5 & -1 & 0 & -1 & 1.10 \\
\hline 6 & 1 & 0 & -1 & 0.45 \\
\hline 7 & -1 & 0 & 1 & 0.95 \\
\hline 8 & 1 & 0 & 1 & 0.56 \\
\hline 9 & 0 & -1 & -1 & 0.41 \\
\hline 10 & 0 & 1 & -1 & 0.83 \\
\hline 11 & 0 & -1 & 1 & 1.11 \\
\hline 12 & 0 & 1 & 1 & 0.82 \\
\hline 13 & 0 & 0 & 0 & 0.57 \\
\hline 14 & 0 & 0 & 0 & 1.10 \\
\hline 15 & 0 & 0 & 0 & 1.02 \\
\hline 16 & 0 & 0 & 0 & 1.01 \\
\hline 17 & 0 & 0 & 0 & 1.01 \\
\hline
\end{tabular}

The multiple regression equation model was obtained:

$\mathrm{Y}=0.94-0.21 \mathrm{~A}+0.023 \mathrm{~B}+0.081 \mathrm{C}-2.5 \times 10^{-3} \times \mathrm{AB}+0.065 \mathrm{AC}-$ $0.18 \mathrm{BC}+0.099 \mathrm{~A}^{2}+0.13 \mathrm{~B}^{2}-0.28 \mathrm{C}^{2}$.

By the Design Expert 8.0.6 software analysis, the optimum condition for flavonoids was: the extraction temperature was $50{ }^{\circ} \mathrm{C}$, ultrasonic power was $400 \mathrm{~W}$, ratio of liquid to solid was 10:1, ethanol concentration was $90 \%$, ultrasonic time was $2 \mathrm{~h}$, under the condition, the flavonoid extraction rate could reach to $1.43 \%$.

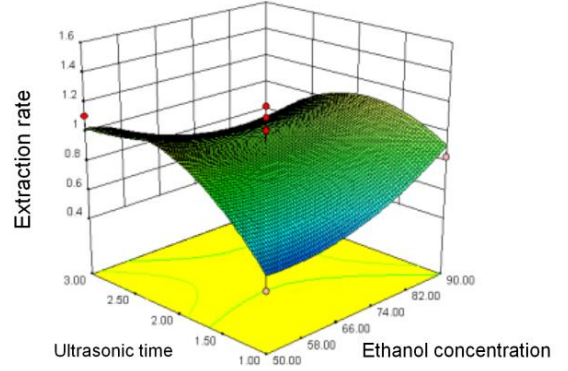

Figure 5. Interaction between ultrasonic time and ethanol concentration on flavonoids extraction rate.

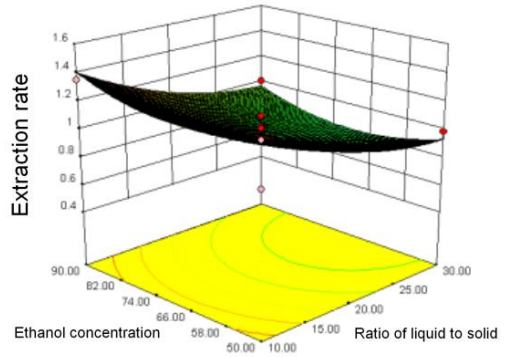

Figure 6. Interaction of ratio of liquid to solid and ethanol concentration on flavonoids extraction rate.

Table 3. Variance analysis of the response surface results.

\begin{tabular}{|c|c|c|c|c|c|}
\hline $\begin{array}{l}\text { Source of } \\
\text { variance }\end{array}$ & $\begin{array}{l}\text { ff Sum } \\
\text { squares }\end{array}$ & ${ }^{\text {of }}$ Freedom & $\begin{array}{l}\text { Mean } \\
\text { square }\end{array}$ & $F$ value & $P$ value \\
\hline Model & 0.97 & 9 & 0.11 & 2.88 & 0.0887 \\
\hline A & 0.37 & 1 & 0.37 & 9.72 & 0.0169 \\
\hline $\mathrm{C}$ & $4.050 \times 10^{-3}$ & 1 & $\begin{array}{c}4.050 \times \\
10^{-3}\end{array}$ & 0.11 & 0.7524 \\
\hline$A B$ & 0.053 & 1 & 0.053 & 1.40 & 0.2746 \\
\hline$A C$ & $2.500 \times 10^{-5}$ & 1 & $\begin{array}{c}2.500 \times \\
10^{-5}\end{array}$ & $\begin{array}{l}6.649 \\
\times 10^{-4}\end{array}$ & 0.9801 \\
\hline$B C$ & 0.017 & 1 & 0.017 & 0.45 & 0.5241 \\
\hline$A^{2}$ & 0.13 & 1 & 0.13 & 3.35 & 0.1098 \\
\hline $\mathrm{B}^{2}$ & 0.041 & 1 & 0.041 & 1.10 & 0.3296 \\
\hline $\mathrm{C}^{2}$ & 0.067 & 1 & 0.067 & 1.79 & 0.2225 \\
\hline Residual & 0.32 & 1 & 0.32 & 8.53 & 0.0223 \\
\hline $\begin{array}{l}\text { Unintended } \\
\text { term }\end{array}$ & 0.26 & 7 & 0.038 & & \\
\hline Pure error & 0.085 & 3 & 0.028 & 0.63 & 0.6327 \\
\hline $\begin{array}{c}\text { Total } \\
\text { deviation }\end{array}$ & 0.18 & 4 & & & \\
\hline
\end{tabular}

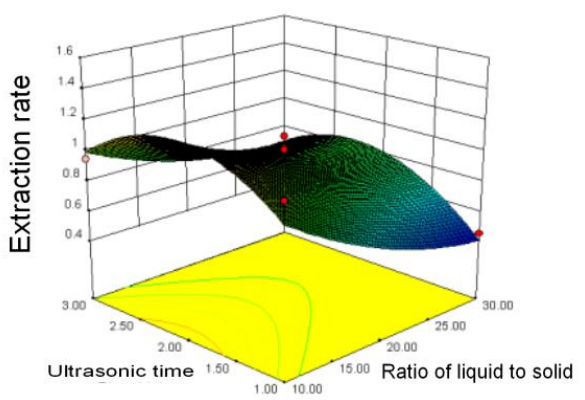


Figure 7. Interaction between ultrasonic time and ratio of liquid to solid on flavonoids extraction rate.

It could be seen from Figure 5, 6 and 7 that three factors ethanol concentration, ultrasonic time, ratio of liquid to solid had the influence on the extraction rate. The best extraction rate could be achieved by seeking the optimal experimental conditions.

\subsection{Color reaction result}

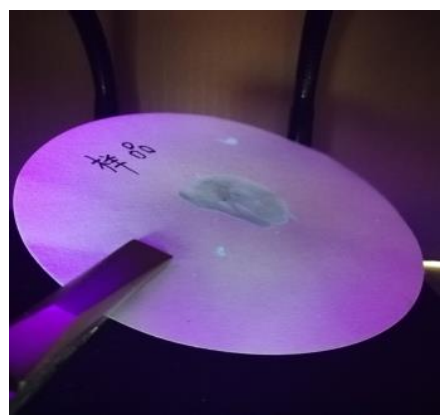

Figure 8. Color reaction under ultraviolet light.

A few drops of sample solution were put on the filter paper and irradiated by ultraviolet lamp. yellow-green fluorescence could be seen, it appeared that the extraction solution contained flavonoids.

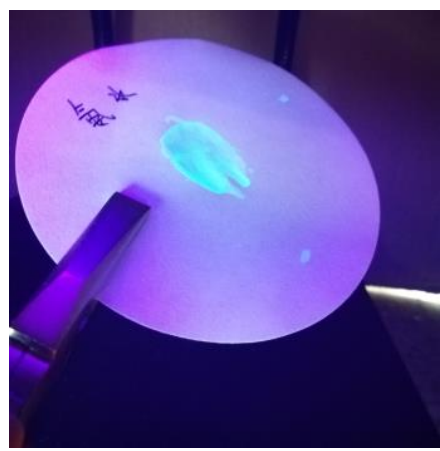

Figure 9. Ammonia water color reaction

A few drops of sample solution were taken and dripped on the filter paper for air drying. Ammonia solution was poured into the small beaker. The filter paper was smoked on the small beaker for $1 \mathrm{~min}$, yellowgreen fluorescence appeared.

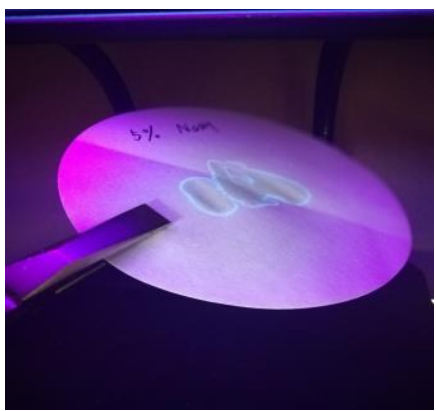

Figure 10. Sodium hydroxide color reaction.

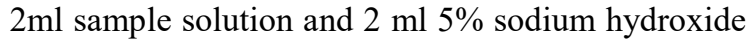
solution were added to observe the color change. Flavonoids would be yellow, orange or red when dissolved in alkaline solution. The result suggested that it might contain both a small amount of flavonoids and a small amount of flavonols.

\section{Conclusions}

This experiment mainly studied the effects of various factors on the extraction rate of flavonoids from Brucea javanica, providing some theoretical basis for its extraction in the food and drug industry. The results showed that for Brucea javanica extraction, when extraction temperature was $50{ }^{\circ} \mathrm{C}$, the ultrasonic power was $400 \mathrm{~W}$, the ratio of liquid to solid was 10:1, ethanol concentration was $90 \%$, ultrasonic time was $2 \mathrm{~h}$, the extraction rate could reach to $1.43 \%$. By color reaction it could be known that the flavonoids extracted from the Brucea javanica were mainly flavonols.

\section{Acknowledge}

This work was financially supported by National Natural Science Foundation of China (project number:U1860112), Liaoning Natural Science Foundation Project (project number: 20170520093, 20170540466), Liaoning Provincial Education Office Service Local Project (project number: 2017FWDF05).

\section{References}

1. Shihui Dong, Jia Liu, Yingzi Ge, Lei Dong, Chenghui Xu, Jian Ding and Jianmin Yue. Chemical constituents from Brucea javanica [J]. Phytochemistry, 85 (1):175-184 (2013)

2. LIxia Fu, Conggang Huang, Minbao Lin and Qi Hou. The research progress of quassionoids components in Brucea javanica and their pharmacological activities [J]. Chinese Pharmacological Bulletin,32(11): 1481-1485 (2016)

3. Mohd-Al-Faisal Nordin, Wan Himratul Aznita Wan Harun, Fathilah Abdul Razak. An in vitro study on the anti-adherence effect of Brucea javanica and piper betle extracts towards oral Candida [J]. Archives of Oral Biology, 7(001):1335-1342 (2013)

4. Seung Mok Ryu, Jaeyoung Kwon, Young Hye Seo, Eun Gyeong Song, Seong Su Hong, Beom Seok Kim, Jin Sung Hong, Ki Hyun Ryu and Dongho Lee. Quassinoids isolated from Brucea javanica inhibit pepper mottle virus in pepper [J]. Virus Research 09(013): 49-56 (2016)

5. Salprima Yudha S, Doni Notriawan, Eka Angasa, Totok Eka Suharto, John Hendri and Yuta Nishina. Green synthesis of silver nanoparticles using aqueous rinds extract of Bruces javanica (L.) Merr at ambient temperature [J]. Materials Letters, 1(114): 181-183 (2013)

6. Chumkaew, Parinuch, Srisawat, Theera. Phytochemical and antimalarial screening of Brucea javanica plant extracts [J]. Journal of Chemical and Pharmaceutical Research, 12: 253-256 (2014) 
7. SRIWILAIJAROEN Nongluk, KONDO Sumalee, NANTHASRI Prance, AUPARAKKITANON Saranya, SUZUKI Yasuo and WILAIRAT Prapon. Antiplasmodial effects of Brucea javanica (L.) Merr. and Eurycoma longifolia Jack extracts and their combination with chloroquine and quinine on plasmodium falciparum in culture[J]. Japanese Journal of Tropical Medicine and Hygiene, 2:61-68 (2010)

8. Anna P. Roswiem, Bambang Kiranadi, Sanjaya Putra Bachtiar and Raafqi Ranasasmita. Antihypertensive Effect of Brucea javanica(L.) Merr. Fruit Extract[J]. Makara Seri Sains, 2: 71-76 (2012)

9. Jiupeng Zhou, Haixia Yang. Meta-analysis on efficacy and safety of Brucea javanica oil emulsion injection combined with chemotherapy for patients with advanced gastric carcinoma [J]. China Journal of Chinese Materia Medica, 41(2): 326-332 (2016)

10. Khalil Hasni, Zul Liham, Surya Dharma, Mahendra Varman. Optimization of biodiesel production from Brucea javanica seeds oil as novel nonedible feedstock using response surface methodology [J]. Energy Conversion and Management, 07(037): 392400 (2017)

11. Haohuan Liu, Bing Zhang, Wu Zhou, Xiangmin Li, Liwen Hu. Anti-tumor effect of Brucea javanica oil [J]. Journal of NanChang University, 1: 22-26 (2017)

12. Fengjuan Han, Dongyan Cai, Xiaoke Wu, Xiaolong Zhai, Long Wang. Research progress of Brucea javanica antitumor mechanism [J]. Journal of Modern Oncology, 3: 669-671 (2013)

13. Min He, Yu Zhou, Jun kuang, Jian-yong Zhu, Li-bo Zhang. Effect of Brucea javanica oil emulsion combined with Aidinjection on non-small cell lung cancer patient's immune function [J]. China Journal of Modern Medicine, 7: 47-50 (2015)

14. ALEX P,DARREN B.Ultrasonic innovations in the food industry:from the laboratory to commercial production[J].Innovative Food Science and Emerging technologies,9(2):147-154 (2008) 